\title{
Educar para el matrimonio en femenino: modelos y prácticas en la literatura de posguerra
}

\author{
Educating women for marriage: models and practices in \\ postwar literaturature
}

\author{
Matilde Peinado Rodríguez; Jose Luis Anta Félez
}

Universidad de Jaén, mpeinado@ujaen.es

\section{Historia editorial \\ Recibido: 27/05/2011 \\ Primera revisión: 02/08/2011 \\ Aceptado: 02/01/2013}

\section{Palabras clave}

Novela rosa

Matrimonio

Ideología

Imagen

\section{Resumen}

La imagen y el modelo de mujer que el franquismo diseñó, impuso y rentabilizó durante más de cuarenta años está siendo objeto en los últimos años de una investigación interdisciplinar donde han confluido Historia, Sociología, Antropología y Didáctica, entre otras Ciencias Sociales; incluso el papel aleccionador de esa imagen no es ajena a los estudios realizados desde el arte, la crítica literaria o la educación. Con esta comunicación nos proponemos aportar nuevos argumentos a esta línea de trabajo desde una nueva vertiente, que tiene que ver con el papel de la mujer como una parte práctica del matrimonio, y que nace de una imagen narrativa que es totalmente detectable tanto en la llamada gran literatura como en su correlato popular la novela rosa. El matrimonio, que no tanto la ulterior idea de familia, mucho más elaborada como idea del patriarcado, supone una forma de discurso permanente del destino, educación y socialización de la mujer. Este momento instituyente, con sus fases basadas en el cortejo, noviazgo y matrimonio, supone una suerte de concentrador del mundo de la mujer, que lejos de tener un papel colateral se convierte en parte de un discurso central. Tratamos de contestar, aunque somos conscientes de que sólo estamos esbozando un camino, en qué medida el matrimonio focaliza y reproduce la idea de la "nueva" mujer franquista, basándonos en los aportes narrativos y teóricos de su imagen en las novelas escritas por y para "la mujer española".

\section{Abstract}

\section{Keywords}

Romance Novel

Marriage

Ideology

Image
The image and the female model that Franco imposed for over forty years is the subject in recent yerars of interdisciplinary research where have converged History, Sociology, Anthropology among other social sciences, like art, literary criticism or education. In this paper we propose to bring new arguments to this line of work from a new aspect, which has to do with the role of women as a practical part of marriage. Marriage, therefore no further idea of the family, much more elaborate as the idea of patriarchy, is a form of permanent address of the destination, education and socialization of women. We try to answer, but we are aware that we are only sketching a way, to what extent marrieage focuses and plays the idea of the "new" woman Franco, based on narrative and theoretical contributions of his image in the novels written by and for "Spanish woman".

\section{Introducción}

El objetivo inicial de nuestro trabajo es realizar un ejercicio de reflexión, dentro de la línea de investigación histórica y antropológica de las relaciones de género, en torno al papel del matrimonio en la articulación del imaginario femenino español de la segunda mitad del siglo $X X$ y, consecuentemente, su repercusión en la vida de la mujer, en términos generales y particularmente en el concepto estético, cultural, institucional, familiar y vivencial del matrimonio hoy. En nuestra trabajo partimos del análisis de las micro-realidades ficcionadas, pero siempre veraces, en una serie de trabajos literarios que muestran

Peinado Rodríguez, Matilde y Anta Félez, Jose Luis (2013). Educar para el matrimonio en femenino: modelos y prácticas en la literatura de posguerra. Athenea Digital, 13(1), 35-46. Disponible en http://psicologiasocial.uab.es/athenea/index.php/atheneaDigital/article/view/Peinado 
de alguna manera el proceso histórico del franquismo y las condiciones materiales de la España desde los años 40 del siglo $X X$ de una modelo de mujer que ha tenido en el matrimonio un modelo tanto ideológico como de práctica y con el que el franquismo creo todo una institución social en el que establecer su concreción política. Un trabajo que va más allá de la crítica literaria para observar, también, el recorrido contextual de una historia de las mujeres, que no siempre ha sido visualizada y que, por ende, se ha visto como marginal y donde el matrimonio, por encima de la idea de familia, es una clave explicativa de primer orden.

La novela rosa ha sido considerada tradicionalmente como una "literatura marginal", incluso se ha definido como sub-literatura, quedando al margen, incluso de los estudios culturales, de ahí que la crítica literaria haya obviado sus potencialidades para el análisis del universo femenino del franquismo. Para la elaboración de nuestro trabajo no sólo hemos considerado imprescindibles las reflexiones de sus protagonistas sino que hemos trabajado de forma sistemática y complementaria con citas, pensamientos y argumentaciones presentes tanto en las obras literarias más referenciadas del primer franquismo (Carmen Martín Gaite, Dolores Medio, Carmen Laforet o Concha Alos) como en la "novela rosa" (Carmen de Icaza, Dolores Becerra, Corín Tellado), una colaboración articulada "extramuros" de jerarquizaciones expertas que ha demostrado cómo el realismo vivencial de la "gran literatura" converge hacia la ficción más arquetípica de los folletines divulgativos: en primer lugar, porque ambos parten de una realidad ficticia, creada, la de un estereotipo de mujer inalcanzable para la inmensa mayoría de las españolas, siendo precisamente su "ilusionada" aspiración uno de los fundamentos de la estabilidad y consolidación del estado franquista; pero también porque ambos géneros plantean una ruptura sutil con los parámetros de femineidad del franquismo, la literatura, con su crítica sutil e implícita a la dominación masculina, y la novela rosa presentándonos mujeres "independientes" que trabajan, leen y luchan por tener un papel propio aún en la sociedad que les ha tocado vivir.

\section{Lectura socioeconómica y jurídíca de la institución del matrimonio}

Su hermana estaba convencida de que el triunfo de toda mujer era conseguir marido «no tener que echarse a la calle a buscar un sueldo». Pasear agarrada del brazo de un hombre que duerma con ella, que gane el dinero que ella gasta (Alos, 1964, p. 249).

El principio de la inferioridad y de la exclusión de la mujer, como reflexionó Pierre Bourdieu (2005, p. 59) que el sistema mítico-ritual ratifica y amplía hasta el punto de convertirlo en el principio de división de todo el universo, no es más que la asimetría fundamental, la del sujeto y la del objeto, del agente y del instrumento que se establece entre el hombre y la mujer en el terreno de los intercambios simbólicos, de las relaciones de producción y de reproducción del capital, cuyo dispositivo central es el matrimonio, fundamento de todo orden social.

La alianza matrimonial es una construcción cultural y por ello las diversas funciones sociales y económicas del matrimonio en el mundo mediterráneo contemporáneo, así como el hecho de estar inserto en estructuras y alianzas sociales, hicieron que la pareja casada sólo pudiera separarse o disolver el vínculo matrimonial dentro de unos límites más bien reducidos, tendencias que se vieron reforzadas desde la Edad Moderna por el creciente control sobre el matrimonio ejercido por las Iglesias y las autoridades civiles, que se cimentó en el corpus legal, tanto religioso como civil, que prohibía el divorcio, una situación que se prolongó a lo largo del siglo XIX en toda Europa, mostrando cómo la inmensa mayoría de sus gobernantes no veía el matrimonio como un asunto personal, sino como una institución pública que sustentaba la estabilidad del orden social, al tiempo que consolidaba en la 
estructura mental social un rechazo a todas aquellas conductas situadas al margen de la norma (Wall, Hareven y Ehmer, 2001).

Estabilidad versus autoridad, la que ejerce el jefe de familia sobre las mujeres y los hijos, a través de dos principios: la mujer obedece a su marido a cambio de protección, una especie de "vasallaje de los afectos", y minoría de edad o incapacitación del colectivo femenino, que las convierte en ciudadanas de segunda, sin plena potestad para ejercer sus derechos y deberes. Como expone Carmen Villanueva Lupión (2007, p. 304) los discursos derivados del Derecho Civil serán utilizados por los autores coetáneos, bajo el manto paternalista y proteccionista hacia la mujer, en su propio beneficio.

El discurso nacionalcatólico, heredero del tradicionalismo más recalcitrante del siglo XIX, es recurrente en el establecimiento de una relación directa entre los males que amenazan la estabilidad y continuidad de, a su entender, el único concepto de familia, católico y patriarcal, cuyo origen unívoco era el matrimonio católico, pero la fuerte impronta ideológica y religiosa de la institución matrimonial que el franquismo recuperó del discurso liberal decimonónico no puede hacerlos olvidar que el matrimonio respondía ante todo, a una necesidad socioeconómica: las mujeres de los colectivos más desfavorecidos veían el matrimonio como una forma de realización de su destino social y cultural, pero fundamentalmente como medio de supervivencia.

Concepción Arenal analizó magistralmente la situación de miseria a la que estaba avocada fácilmente la mujer de su época sin la tutela de un hombre. Esta dependencia era toda una fuente de desventuras:

La joven mira por su porvenir: muerto su padre, casados sus hermanos, le espera la pobreza, tal vez la miseria o el amargo pan que le dé una cuñada; la soledad material y moral de quien recorre la triste escala de no ser necesaria, ser inútil, ser un estorbo; ve su destino de vestir imágenes y su apodo solterona, y se casa sin amor, tal vez sintiendo aversión por el hombre que ha de ser su compañero hasta la muerte. (Lacalzada de Mateo, 1994, pp. 104-105).

Ante este panorama la mujer no tenía más carrera que el matrimonio, que se hacía imprescindible para las mujeres de clase media y baja.

Las posibilidades de autosuficiencia económica de una mujer célibe, en este periodo, eran manifiestamente limitadas a medida que descendemos en la escala social, pero las transformaciones económicas, políticas, sociales y culturales que se producen en el último cuarto del siglo XIX y, fundamentalmente, en el primer tercio del siglo XX, evidenciaron los primeros atisbos de cambio y evolución en la trayectoria social y personal de las mujeres, derivados prioritariamente del incremento de la demanda de trabajo femenino, de carácter doméstico e industrial por parte de los núcleos urbanos, que hacen posible su incorporación a la red de flujos migratorios que hasta el momento habían protagonizado los hombres, ampliando las posibilidades de subsistencia para aquellas mujeres carentes de recursos, que pudieron permanecer solteras sin que dicha condición implicara la posterior dependencia económica de otros miembros de la familia:

"La señorita Quintana era el clásico tipo de solterona de clase media del primer cuarto de siglo: parásito de la hermana casada, alcahueta de sus sobrinos, sentimental, inocente, un poco cursi" (Medio, 1953, p. 74).

Ahora bien, el parasitismo ¿era una condición asociada de forma exclusiva a la soltería femenina o era una condición "innata", necesaria para garantizar la sumisión y dependencia de la totalidad del colectivo 
femenino? " [...] ser un parásito. Vivir como una mariposa dando vueltas en torno a los machos y poder dormir con ellos: eso quería" (Alos, 1964, p. 241).

Sin embargo, la incorporación al mercado laboral no era una salida "digna", "propia de su condición" para las mujeres de clase media: si no se casaban, pues, ciertamente, el matrimonio no estaba siempre al alcance de todas, los prejuicios sociales y propios les impedían trabajar fuera del hogar, y además, su educación, similar a las mujeres de clase alta, tampoco les proporcionaba conocimientos útiles para participar del mundo laboral:

Las chicas sin novio andan revueltas a cada principio de temporada, pendientes de los chicos conocidos que preparan oposición a Notarias. Casi todas estaban de acuerdo en que era la mejor salida de la carrera de Derecho, la cosa más segura. A lo mejor a los treinta años estás casada con un Notario de Madrid ¿tú sabes lo que es eso? (Martín Gaite, 1968, p. 162).

Frente a los ligeros indicios de cambio en el mercado laboral femenino y, fundamentalmente en las posibilidades de emancipación de la mujer, el estado franquista necesitaba recuperar la visión trágica, esperpéntica, digna de lástima, de la mujer soltera, cuyas ansias de "volar en solitario" podían dar al traste con el patriarcado que tan bien servía a los intereses de la patria, que necesitaba hijos sanos y fuertes, a los del Estado, donde organización económica y laboral descansaba en un mercado laboral en clave masculina y a los del nacionalcatolicismo, cuyo modelo de mujer que vegetaba, callada y servilmente, a la sombra del hombre o en la maternidad espiritual de la vida consagrada.

\section{El matrimonio como narrativa}

En el mundo distorsionado y confuso de la Postguerra española el papel de la mujer, un papel previamente establecido y cerrado en sí mismo, estaba siempre en relación al modelo social y político de familia. Esta se había convertido en una institución de primer orden en el discurso del nuevo gobierno franquista, aunque como tantas otras cosas estaba en relación a unos orígenes negociados anteriormente en el pacto socio-religioso nacido, por un lado, de las teorías político-sociales de la dictadura de Primo de Rivera y, por otro, de la reacción contraria al modelo social (y por ende, pero especialmente, al de familia) propugnado desde la II República. Esta institución nacida de la reacciónafirmación era, consiguientemente, el mundo en el que vivían las mujeres, cuando menos, en las dos primeras décadas del franquismo. Las mujeres nacían y morían en ella, centraba su vida individual y social, les daba una identidad y una referencialidad. Sociológicamente era su marco, su único marco. De hecho podemos entender que esta institución era para las mujeres un cierto texto de sus vidas. Un texto en la medida que una relación de elementos simbólicos, altamente codificados, y que conforma una unidad de sentido. La familia como texto establece un doble juego: se trata de un lugar donde los elementos conforman algo que forma parte de un orden social y es aprehensible normativamente. Esta textualidad planteada por la familia daba a las mujeres, cuando menos, un espacio social pre-establecido y un sistema de codificaciones que permitía situarla dentro de los esquemas de subordinación de lo social que había planteado el discurso político-religioso.

Lo que nos resulta más interesante y que en última instancia constituía un reto que se habían apresurado a resolver las escritoras de novela rosa, es que la idea de familia era un hecho claramente abstracto como práctica, de alguna manera había una incompatibilidad entre la idea de familia, que es un estado de las formas institucionales de una sociedad, y su consecución práctica. De ahí la introducción de ese elemento que era el matrimonio, una forma jurídica que estaba llena de fases, símbolos y 
momentos. El matrimonio era el leitmotiv de las novelas, incluso de muchas de las novelas consideradas alta literatura, y el lugar práctico donde se juntaba en el mismo plano la idea ficcionada de un lugar para el amor y las posibles ambiciones de la realidad de la supuesta lectora. El matrimonio era el continuo que unía todos esos dispersos trozos (autora, obra, personajes, situaciones, lectoras, códigos políticos y religiosos) de realidad-ficción que la novela rosa suponía.

Pero es más, al proponer que el camino de la familia era el matrimonio se ponía sobre la mesa la importancia de una sociedad que se basaba en un orden jurídico, religioso y conservador. Esta manera de ver el matrimonio como fin y como vía establecía que el papel de la mujer era, en cierto sentido, secundario, a la par que situado y concreto en un saber que no dejaba más aire que el de un modelo cerrado y arquetípico. El matrimonio, con sus fases basadas en la fijación de un orden social bajo la idea sentimental del amor, el noviazgo, la pedida, el casamiento, la noche de bodas [...] y sus prácticas, siempre tan corporales, económicas, políticas e institucionales, era un lugar plenamente visible que servía de referente y de modelo.

Las novelas rosa explotaban esta idea, amasando una serie de tópicos de diferente orden y con un ideal de mujer siempre en un mundo moralmente bipolar, con unos ideales políticos y religiosos que no sólo fijaban el ideal del amor sino que le daban la textura para que fuera creíble. Porque la novela rosa del franquismo es muy creíble, es intrínsecamente verdad y coetánea al orden político que la rodea tanto como a sus lectoras. La idea es que sólo puede ser así porque socialmente es así, y la verdad, fuera de que la ficción propone un marco muy cerrado, y es que al proponer una idea clara con respecto al matrimonio, por encima de la familia, todo se convierte en un gran contenedor de una propuesta social muy determinada, conocida y ambicionada. A nadie se le escapa que la obra Usos amorosos de la Postguerra española, de Carmen Martín Gaite (1994) y coetánea de Corín Tellado, puede ser leído no sólo como un ensayo, sino que es también una guía muy precisa de cuáles son los ideales de un mundo y, consiguientemente, un extraño manual (de ahí lo de usos) para conseguir el matrimonio en un tiempo atormentado y complejizado; pero también como el exoesqueleto de una novela rosa. Por lo tanto es obvio que cuando hablamos de mujer en la Postguerra el tema se centra en la idea de que el matrimonio es, obviamente, el lugar clave.

Si la familia es una ficción que se reproduce en la realidad social, el matrimonio sería una realidad social que tiene la capacidad de reproducirse en los mundos ficcionados de la literatura, el cine y la televisión. Durante la Postguerra española el matrimonio se convirtió, además, en el único refugio socialmente posible para la mujer, el único espacio donde la mujer podía desarrollar un papel social. De esta manera daba lugar a una fuerte narratividad, por un lado, porque sus fases, del contacto al noviazgo, del compromiso al matrimonio, de la noche de bodas a la luna de miel, estaban tan codificadas y llenas de elementos sociales que era difícil no verlo como un lugar ideal para el drama, la comedia y el erotismo, todo ello con la facilidad de crear un mensaje moral y modal al respecto. Pero, por otro lado, al devenir en una práctica social tan ritualiza y sentimentalizada el deseo y la frustración se deban en la misma medida como un modelo de lo posible, como en un esquema de lo que ocurre. Y si el matrimonio se dio como el lugar no podía ser más que lo que el conjunto social asumía como el espacio natural de la prácticas de la mujer. Un espacio esquizoide y poderoso que invisibilizó al conjunto de las mujeres en una carrera al servicio de unos ideales, sentidos y formas preñadas de ideología política y religiosa.

Independientemente del hecho nada baladí de que la novela rosa de la Postguerra fue una reacción epidérmica y frontal contra el ideal de mujer establecida en la II República como en el periodo de la Guerra; pero ese ideal, que sirvió de gran contra-modelo también ofreció la posibilidad de profundizar en dos apartados nuevos y que tanto la novela, como el conjunto social, más o menos, explotó hasta hacer 
casi natural: por un lado, la idea de que la mujer también tenía un mundo social, relacionado con su papel en la iglesia, entre pares (las amigas), con el mundo comercial (ir de compras y comprar se convirtió en un labor de la "nueva" mujer) y la ayuda social. Y, por otro, con la idea, de que el matrimonio era un mundo lleno de posibilidades para la mujer, un lugar que "bien" explotado le proporcionaría todo un conjunto de realidades maravillosas y felices. Este territorio era obviamente siempre de subordinación, eso nadie lo negaba, ni las novelas rosa más extremas, de la misma manera que se suponía como parte del orden social, de un orden que ni se cuestionaba, ni se negaba, ni se criticaba. Por el contrario, estas proporcionalidades que planteaba este modelo de "nueva" mujer tenían sentido en el matrimonio, pero también para el matrimonio.

El matrimonio se había convertido en un lugar, reconocido y deseado y, consiguientemente, tenía algo de tangible, visible, tocable. Es verdad que era un bastión para el hombre y sus ideales patriarcales, pero de alguna manera al plantearlo como el espacio natural de la mujer le daba una "apariencia" de feminidad, con una estética muy centrada en fuera lo que fuera que definía a las mujeres. Autoras como Corín Tellado o Carmen de Icaza veían sus novelas como territorios de la experiencia del amor para mujeres que de alguna manera buscaban un mundo propio. Ellas, aun cuando tuvieran una identidad prácticamente absoluta con los presupuestos del régimen de Franco, no dudaban en verse a sí mismas como las dinamizadoras de una sociedad que le había dado a la mujer una identidad, incluso un espacio propio, con un sentido tanto moral cuanto más estético.

\section{La mujer casadera: entre la aspiración y la desesperación}

Cuando unimos tres cosas: primero, atracción natural entre sexos opuestos, segundo, dependencia de la mujer hacia el marido, siendo regalo suyo todo privilegio o placer que tiene o dependiendo totalmente de su voluntad, y en último lugar, que el objeto principal de la búsqueda humana, la consideración, y todos los objetivos de la ambición social, ella sólo puede obtenerlos o pretenderlos a través de él sería un milagro si el fin de ser atractiva a los hombres no se hubiera convertido en la estrella polar de la educación y formación del carácter femenino (Stuart Mill y Taylor, 2001, p. 164).

Ante la evidencia de que la mujer carecía de proyección personal y significación individual, y que su razón de ser, esposa y madre, tenía origen y destino en otro, su futuro marido, podemos afirmar que la única capacidad en la que debían batirse a título personal era su habilidad para encontrar esposo, una carrera desesperada en la que las mujeres, "ese problema social" para todos aquellos progenitores con hijas casaderas, necesitaban solucionar su porvenir, su situación en el ámbito comunitario y la guarda y custodia de su honra:

Margarita se dejaba hacer con un cierto fatalismo, suponía que los hechos tenían que transcurrir así y desembocar en una boda. Intuía que permitir ciertas libertades y mantener a raya según qué actos podía ser una especie de cepo para llegar a la meta, la suprema aspiración femenina. El santo matrimonio .El matrimonio. Todas las novelas que había leído acababan al pie del altar. Muñequita, Los cien caballeros de Isabel la Católica, Cristina Guzmán. [...] Había que casarse. Era el triunfo de la mujer. Los hombres tenían metas más variadas: una carrera brillante, la necesidad de ganar dinero, la posición social a conquistar. Nacer chica eximía de estas luchas. Bastaba ser lo suficientemente bonita y lo bastante astuta para conquistar un hombre. Después una alfombra felpuda, blanda, podía extenderse a los pies de la afortunada. Una alfombra para caminar toda la vida por ella. Para tumbarse a la bartola (Alos, 1969, p. 212). 
Gustar a los hombres, posicionarse bien en el mercado matrimonial, era el baluarte principal de la formación de las mujeres de clase alta y media, y una utopía ilusionante para las clases populares, a las que la literatura y la novela rosa les brindó toda una suerte de historias de amor de señoritas de clase baja que enamoraban a ricos, que la convertían en reinas, reinas de su hogar:

Le gustaría casarse con un rico, pero el asunto está verde. Su madre le decía "si te casas que sea porque te guste hacerlo, no para que te mantengan"; como si fuera fácil zafarse del matrimonio y decir que no a una casa propia, un mandar la propia persona, un pasearse del bracete formando matrimonio con alguien, sea el que sea. ¿Enamorarse? Bueno, quizá eso era lo mejor, pero lo normal sería que no pudiera escoger, que tuviera que conformarse emparejando con el que se acercara (Alos, 1969, p. 104).

Cuando se alcanza la edad de merecer, todo un universo de enseñanzas y consejos planean sobre estas jovencitas: la moda, la belleza, los consultorios sentimentales, los relatos amorosos... todos convergen al binomio amor-matrimonio como el camino hacia la felicidad. Sin embargo, desde parlamentos superficiales, materiales que, lejos de profundizar en las relaciones o instituciones humanas recurren de nuevo, en la inmensa mayoría de los casos, a las formas, al decoro, a los modales, siendo el trasfondo de todos los miramientos y cuitas, la castidad femenina, revestida de pudor y recato, atribuyendo a aspectos formales, materiales, comportamentales o incluso gestuales, en numerosas ocasiones de enorme trivialidad, cualidades morales y moralizantes, que en el caso del colectivo femenino eran revestidas de enorme trascendencia, al hacer depender de ellos el éxito del cortejo.

Una "mujer para casarse" se le nota en lo pulcra, ordenada, equilibrada, sencilla, íntegra y prudente (Sopeña, 1996, 37), pues los hombres, aunque buscaran el entretenimiento que proporcionan las relaciones con mujeres fáciles, elegirian para esposa a una mujer de cualidades semejantes a su madre:

Las virtudes de una esposa ejemplar: hacendosa, caritativa que prepare bien la ropa y comida del esposo y de toda la familia. Buscad para novia primero, después para esposa, una chica que se parezca a ese modelo de mujer y madre. No os engañéis mirando sólo la presencia o la simpatía de los jóvenes. Mirad que bajo una apariencia grata puede ocultarse una mujer holgazana y presumida, gastadora e inútil. Vosotras, jovencitas, imitad cuanto podáis a ese modelo augusto. (Junquera, 1961, p. 42)

A toda madre con hijas casaderas corresponde la ardua misión de velar por la castidad y el recato de sus hijas:

A los chicos debes tratarlos con naturalidad, sin desenfado ni naturalidades excesivas, con una mezcla de confianza y respeto [...] estarás siempre muy en tu puesto [...] Prefieren hallar en ti lo que ellos no tienen; la gracia, el pudor recatado y el encanto de una muchachita que sabe ser camarada sin dejar de ser a un tiempo muy muchacha. (Gómez Alonso, 1944, p.16).

Y, así, inculcar sabiamente en ellas las virtudes que han de tener los posibles pretendientes, cuidar meticulosamente sus formas en los encuentros con varones, en los actos sociales, etc. Las madres deben ser el espejo pulcro en el que sus hijas aprendan como hay que amar, honrar, obedecer y procurar el bienestar de sus futuros maridos.

La obsesión enfermiza por el control de las relaciones sexuales y la conservación de la virginidad, de las mujeres, hasta el matrimonio, se vehiculizaba a través de la vigilia permanente sobre el cuerpo femenino 
para garantizar el dominio de la descendencia adscrita al patriarca, un juego de intereses creados donde no bastaba con adoctrinar a la juventud con discursos paternalistas sobre la benevolencia del amor espiritual, de la entrega desinteresada, del amor único y verdadero; era necesario la alienación, la interiorización, la naturalización a través de la amenaza:

Si accedes a los requerimientos carnales de tu novio, lo más probable es que él, después de dar satisfacción a sus efusiones, te abandonara. Casarse con una mujer pura es la máxima aspiración de cualquier hombre, quien se guardará mucho de convertir a una joven que no sabe comportarse dignamente en su esposa y madre de sus hijos. (Sopeña, 1996, p. 66).

Pero la edad de merecer es limitada para las mujeres, acuciadas por su reloj biológico y por un Estado pronatalista que ve, en las mujeres jóvenes, potenciales madres de descendencia numerosa. Como expone Josefina Aldecoa (2006, p. 87) "tenía veinticinco años y todas las chicas de mi edad, las amigas de la infancia, se habían casado ya o habían aceptado quedarse solteras". Aceptar la imposibilidad de alcanzar la máxima aspiración de toda mujer, la única realidad para la que habían sido educadas, las convertía en agonizantes féminas, como Doña Rosita "la soltera", que había renunciado a la propia vida en vida, o desesperadas mocitas viejas, caricaturizadas en tantas obras literarias:

Cinco muchachas que lucían a todas horas los últimos modelos de la moda, y cinco sonrisas que habían ido estrenando al hacerse mujeres. Cinco sonrisas que iban sabiéndoles a desilusión, a medida que pasaban los años sin que lograsen encontrar un novio. El Señor de Girald velaba celosamente por aquellas cinco sonrisas, que estaban convirtiéndose en cinco muecas (Medio, 1953, p. 44).

Las niñas y adolescentes debían elegir entre el amor profano o el sacro, el matrimonio con un hombre o con Dios; permanecer soltera no era entendido como una opción y, por tanto, las solteronas que habían sido incapaces de participar del mercado matrimonial eran un arquetipo femenino extraño al cuerpo social: seres desnaturalizados, amputados, dependientes, dignas de lástima:

Huesos dislocados son esas pobres mujeres que, después de haber fracasado en cuantos intentos han realizado por casarse, se ven precisadas de permanecer solteras y no se resignan, y se vuelven furiosas contra su destino, sin acertar a mirar a lo alto. Son unas desgraciadas, su vida está llena de amarguras. Por sus ridiculeces se prestan al chiste, y por su egolatría resultan impulsivas. A base de ellas se ha forjado la novela (Enciso, 1945, p. 34).

Hemos interiorizado y naturalizado esta imagen de tal suerte que las importantes transformaciones educativas, laborales, sociales y culturales en pro de la emancipación de la mujer no han conseguido desterrar la visión lastimera y paternalista de las mujeres que afrontan su vida en solitario en la que podríamos reconocernos todos; cuarenta años de automatismo ideológico no pueden ser desterrados tan fácilmente: "El santo de las niñas es San Gregorio, y ya podéis pedirle que os de un novio, si, que os de un novio". (Medio, 1953, p.115).

\section{La estética del enlace}

La estética del matrimonio que plantean las novelas rosas en la Postguerra fuera como fuese tenía un momento crítico: dado que se contraponía a una mujer libre e independiente, un ideal que de alguna forma administró la República, sin preocuparse demasiado de si era verdad o no, se fundamentaba unos 
valores que no se centraban en un espacio concreto y determinado para la mujer. De esta manera la novela rosa, al proponer un lugar ideal para la mujer, la dotaba de un contenido social directo, donde de alguna manera ella era la dueña de su realidad. Mucho del éxito de la novela rosa, tanto en autoras, número de obras e, incluso, colecciones de este momento, reside en que todas en líneas generales proponen algo relativamente esperanzador: la mujer casada tiene un derecho social superior. Esto significaba que la mujer tenía un cierto momento de empoderamiento que no era del todo lo que las mujeres de la época vivían, fueran de la clase que fueran, y donde parecía que el "entendimiento" entre géneros era posible. De hecho estas novelas proponen que tras el sentimiento del amor sólo puede darse una cierta y concreta institución ritual: el matrimonio. Lo interesante de la propuesta, con respecto al matrimonio, de la novela rosa, es que este era un mecanismo que permitía legitimar la invisibilidad de la mujer tras el apoyo incondicional y amoral (siempre en nombre del amor) a un solo hombre. Pero a su vez marca una cierta ruptura con los presupuestos más conservadores del Nacional-catolicismo: la mujer escribe, la mujer lee y la mujer tiene un papel social propio.

Enmarcado en una supuesta cultura popular, la novela rosa es también un momento muy interesante de los elementos que conforman la idea de un mundo interclasista, interfamiliar y prácticamente universal. Sin embargo, tanto para la cultura más oficial, como para los mundos críticos y elitistas de la gran literatura, la novela rosa era despreciada en la medida en que era una cosa de "mujeres". En este sentido ya no es sólo la novela rosa, es la propia práctica experimental la que propone que el matrimonio es algo que supera con mucho a lo que se afirma desde casi cualquier otra posición ideológica, es tanto un deseo cuanto más una realidad que tiene la capacidad de crear tanto una estética, como la forma narrativa que hemos descrito.

El matrimonio es, en este sentido, un hecho social total. Un lugar que sirve de referente y modelo para el resto de los elementos que definen y conforman la realidad social más general. De esta manera el matrimonio da la posibilidad de que la mujer se haga sujeto social, la confiere protagonismo y aparente visibilidad. Un planteamiento que se alejaba de los ideales de la mujer de la República, pero que marcaba también unas sutiles diferencias con la mujer propuesta por el ideal franquista y que, a la postre, creó unos usos e ideales muy estéticos. Centrado en la novela rosa, pero también en su propia idea de experimentalidad, el matrimonio tomaba la forma estética que desde su mismo momento significó: un lugar para la práctica subjetiva del estar mujer.

De eso se trata, el matrimonio era el performance que unía el ideal de espacio femenino de la nueva mujer del franquismo a la par que el ideal de las novelas románticas de la época. De ahí su éxito y la hipotética universalidad del matrimonio (de la que se aprovechó la propia novela rosa, el régimen franquista, la Iglesia Católica o las creencias populares afirmativas de las bondades de la idea de familia), es un meta-género para los géneros, es una estética narrativa, es la disolución de todas las ideas, en lo social puede considerarse una aspiración, en lo personal un deseo, en lo ideológico una tecnología concreta para el control y definición del universo.

En cuanto sistema de ideas narradas y vividas en la estética del color blanco, el rosa y el rojo pasión, que centra un complejo sistema al servicio del biopoder, el matrimonio encontró en la novela rosa un lugar privilegiado para su difusión como idea única y posible. Por otro lado, el matrimonio planteado desde la posición política de la novela rosa daba una serie de indicaciones de carácter generacional, con la idea de que el destino era llegar a constituir un cuerpo social superior, una cierta familia en lo nacional y un matrimonio con los compromisos de una sociedad mercantilizada y políticamente controlada. No en vano, el matrimonio era, de alguna manera, un lugar para una utopía fémina, basada en una supra-teoría de clases sociales cimentada en la idea del mercado como verdadero regulador de las relaciones 
humanas. Esta es en cierta medida la gran novedad que plantea la novela rosa de la postguerra, introduce "la creencia" de que el matrimonio nunca sería una mentira si era por amor, pero para que este se diera tenía que ser en un contexto en que el mercado fuera el centro de todo. Como elemento biopolítico de la revolución social planteada por el primer franquismo el matrimonio era un lugar que partía de las economías para llegar a una explicación total en y para el mercado. No era ya una cuestión de clase, que también, era sobre todo que el conjunto social admitía como único camino la mercantilización de la realidad social, de su mundo, fuera cual fuera el punto de partida o el de llegada.

El matrimonio, de esta manera, era el lugar idóneo para la mujer sirviera a los proyectos biopolíticos del nacionalcatolicismo, a la par que se convertía en uno de los muchos puntos donde la economía de mercado se hacía fuerte. De hecho, toda esta idea del matrimonio tenía que darse en un lugar, en un espacio, en última instancia, en una casa con cocina, salón con tresillo y dormitorio; el matrimonio no era, ya entonces, un simple lugar institucional, sino que tenía toda una estética física y aprehensible. De la misma manera que el matrimonio terminaba por generar no sólo un lugar para la mujer, sino un espacio realmente natural, el lugar donde había de tener a sus hijos y consecuentemente donde se invocaba a la magia social de la reproducción del mundo tal cual tiene que ser. Se cierra el ciclo, la mujer enamorada se convierte en madre gracias a una fuerza nueva, el amor, que tiene un espacio nuevo, el matrimonio, para una ideología renovada, el nacional-catolicismo.

\section{Concluyendo}

Pero al final, el matrimonio tanto en la práctica social como en la novela rosa es una derrota para la mujer, el amor que parecía ser la invocación última de todo es una ectopia, un órgano fuera de lugar, y aunque cumple con su función lo hace de manera descolocada, en un lugar del plano que no le corresponde, tomándose atribuciones que de alguna manera tienen que ser reubicadas. En última instancia, el matrimonio es un aparato legal, un artefacto religioso y un concentrador de la ideología del dominio del Estado, en masculino, en patriarcal. Es una historia, por lo demás, conocida, donde las instituciones sociales se ponen al servicio de una única ideología y donde la derrota se anuncia como una victoria. En el distorsionado mundo del franquismo la mujer era un peligro, una idea, un ideal y una supeditación: para el matrimonio, no por amor, sino por servicio a la nación. En la España-cuartel de Franco todos tenían una misión y un lugar, un cometido y una función, todos y todas vivían en la ficción, ya fuera de la Iglesia Católica, de la literatura o de la política. Y por eso mismo es curioso, pero no por ello menos cierto, que para muchos españoles de la época el único momento de libertad, de ser ellos mismos, de sentir algo, fuera cuando ellos acudían al Servicio Militar y ellas a su colaboración con la Sección Femenina. Curioso mundo donde ficción y realidad, libertad y control, amor y deber, matrimonio y familia se fundían y mezclaban para que la verdad fuera, definitivamente, una construcción biopolítica.

La novela rosa, esa manera concreta de mostrar una narrativa hecha literatura y donde los personajes tomaban su fuerza de un sentimiento, el amor romántico, en función y beneficio del matrimonio, fue un vehículo de las ideas con respecto a lo que se pensaba del papel y el lugar de las mujeres. Pero esta literatura también fue un extraño espejo donde un buen número de mujeres desearon que el mundo, su mundo, se pareciera a otros que eran sólo parte de una ficción novelada. De la confusión de ambos mundos y de la enorme distancia entre el deseo y las prácticas la España franquista de la postguerra creó un modelo, más bien unas formas, que permitieron tener un referente para los sistemas institucionales de poder y una aspiración para las clases sociales menos favorecidas y que el matrimonio era la única opción de vida (Anta, 2009, pp. 100-108). En conclusión, la novela rosa puede que sea un espejo del matrimonio, pero también un posicionador del lado en que se está en aquella sociedad que 
había planteado un papel para cada individuo. Un mapa y un manual de la mecánica social que exceden lo que el papel de las novelas rosas proponían, para caer en una realidad muy concreta: la sumisión de la mujer a las estructuras de poder, concretadas en la estética y ritualización de la institución del matrimonio.

En última instancia, como hemos mostrado en este trabajo, las redes de sumisión en que vivieron las mujeres durante la postguera son también de resistencia y las formas creativas que utilizaron no estaban en el guion de las novelas rosa, ni siguiera en la ideología de instituciones como la Sección Femenina. El matrimonio, como cualquier otra conceptualización del poder donde las relaciones humanas son determinantes, termina por ser un lugar para entender, también, la confrontación. Y el relato humano de este periodo es otro, la mujer buscaba también un mundo propio lleno de valores que conforman una realidad que no sólo estaba llamada a su reproducción sino ante todo a su transformación, ya fuera por habitado, por real o, simplemente, porque el entramado complejo y continuado de las prácticas paternalistas y patriarcales ya no tenía sentido y donde todo quería ser nuevo y transformado, más profundo y bello. Educar para el matrimonio fue, en definitiva, una educación para lo real más allá de lo que pudo y produjo los ideales de las instituciones sociales que vivieron al calor de la novela rosa del poder franquista. Definitivamente las mujeres encontraron algo por lo que luchar, pero también desde el que establecer una identidad propia: el matrimonio, ese lugar oscuro y sumiso, fue un fracaso y un tiempo de negación de la mujer, y por eso mismo, como en el juego de espejos que se había planteado con la novela rosa, fue la principal atalaya política desde el que muchas mujeres algunas décadas después determinaron que era el lugar preciso y concreto desde el que plantear su liberaron.

\section{Referencias}

Aldecoa, Josefina (2006). Historia de una maestra. Madrid: Alfaguara.

Alos, Concha (1964). Las hogueras. Madrid: Plaza y Janés.

Alos, Concha (1969). La madama. Madrid: Plaza y Janés.

Anta Félez, José-Luis (2009). Para una antropología del amor. La novela rosa y los productos de la cultura de masas. En Alicia Gil Gómez, Gemma Escrig Gil y Ana Forcada Martínez (Eds.), Poder, poderes y empoderamiento... ¿y el amor? jah, el amor! (pp. 100-108). Castellón: Fundación Isonomía; Universitat Jaume I.

Bourdieu, Pierre. (2005). La dominación masculina. Barcelona: Anagrama.

Enciso Viana, Emilio (1945). iMuchacha! Madrid: Ediciones Studium de Cultura.

Lacalzada de Mateo, Maria José (1994). La otra mitad del género humano vista por Concepción Arenal (1820-1893). Málaga: Atenea.

Martín Gaite, Carmen (1968). Entre visillos. Barcelona: Destino.

Martín Gaite, Carmen (1994). Usos amorosos de la Postguerra española. Barcelona: Anagrama.

Medio, Dolores (1953). Nosotros, los Rivero. Barcelona: Destino.

Sopeña Monsalve, Andrés (1996). La morena de la copla. Madrid: Puzle.

Stuart Mill, John y Taylor, Harried (2001). Ensayos sobre igualdad sexual. Valencia: Cátedra.

Villanueva Lupión, Carmen (2007). El principio de igualdad entre mujeres y hombres y el Derecho civil. En Pilar. Fernández Pantoja y $\mathrm{M}^{\mathrm{a}}$ José. Cruz Blanca (Coords.), Igualdad de oportunidades y conciliación: una visión multidisciplinar (pp. 303-336). Jaén: Universidad de Jaén.

Wall, Richard; Hareven, Tamara K. y Ehmer, Josef (2001). Family History Revisited: Comparative Perspectives. Newark, DE: University of Delaware Press. 


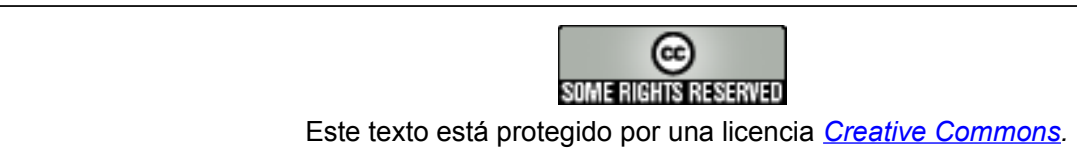

Usted es libre de copiar, distribuir y comunicar públicamente la obra bajo las siguientes condiciones:

Reconocimiento: Debe reconocer y citar al autor original.

No comercial. No puede utilizar esta obra para fines comerciales.

Sin obras derivadas. No se puede alterar, transformar, o generar una obra derivada a partir de esta obra.

Resumen de licencia - Texto completo de la licencia 